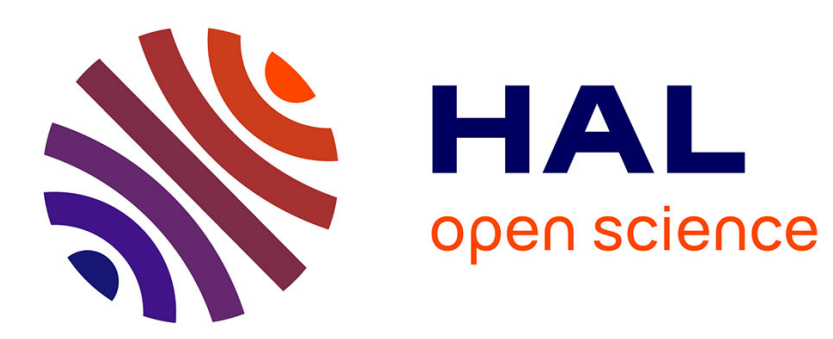

\title{
Rawls's influence and counter-influence on Sen: post-welfarism and impartiality
}

\author{
Muriel Gilardone
}

\section{To cite this version:}

Muriel Gilardone. Rawls's influence and counter-influence on Sen: post-welfarism and impartiality. European Journal of the History of Economic Thought, 2015, 22 (2), pp.198-235. 10.1080/09672567.2013.792365 . halshs-00770886

\section{HAL Id: halshs-00770886 https://shs.hal.science/halshs-00770886}

Submitted on 14 Dec 2018

HAL is a multi-disciplinary open access archive for the deposit and dissemination of scientific research documents, whether they are published or not. The documents may come from teaching and research institutions in France or abroad, or from public or private research centers.
L'archive ouverte pluridisciplinaire HAL, est destinée au dépôt et à la diffusion de documents scientifiques de niveau recherche, publiés ou non, émanant des établissements d'enseignement et de recherche français ou étrangers, des laboratoires publics ou privés. 
Research article accepted for publication in The European Journal of the History of Economic

Thought, Vol. 22:2, April 2015, pp. 198-235.

Rawls's influence and counter-influence on Sen: Post-welfarism and impartiality Muriel Gilardone ${ }^{1}$

Université de Caen Basse-Normandie, CREM UMR CNRS 6211, France.

\begin{abstract}
This article aims to clarify Sen's paradoxical relationship to Rawls's work in the face of some misconceptions. It is argued, first, that the dialogue between the authors did not start with Sen's 1980 article "Equality of What?": rather, this article represents the beginning of a transformation in Sen's position towards Rawls. Second, Sen's approach to justice is not a mere extension of Rawls's theory of justice as fairness: the departure relies less on a different metric of justice than on a divergent conception of impartiality, one which undermines the foundation of Rawls's theory of justice.
\end{abstract}

Key-words: Sen, Rawls, Interpersonal utility comparisons, social choice, justice.

JEL classification code: D63, B31, B41

\title{
0. Introduction
}

The influence of John Rawls on Amartya Sen's philosophical work is obvious, particularly on those aspects of his work which concern justice and equality. It is well known that Sen's development of the capability approach was motivated by a desire to extend the structure of the Rawlsian theory of justice as fairness, by moving the informational basis from primary goods to capabilities. Indeed, from 1979 to at least 2000, the figure of Rawls is associated in Sen's writings with the debate over the measurement of individual advantage within accounts of social justice. Ingrid Robeyns (2009) provides a good summary of this debate and defends the view that Sen's capability approach is complementary to (and therefore consistent with) Rawls's theory of justice as fairness. However, since the publication of Sen's The Idea of Justice (2009), it has become clear that the relationship between these authors is more complex than commentators had thought: while Rawls is omnipresent in this book, he now appears as a straight opponent, not simply as someone with whom Sen is in dialogue regarding the specific question of individual advantage. Furthermore, Sen no longer insists on the capability approach and focuses rather on the procedures which engender justice.

1 The author would like to thank Antoinette Baujard and Herrade Igersheim for stimulating and constructive discussions, Maurice Salles Joseph Siani and Ben Young for their kind proofreading, and two anonymous referees for their valuable comments on the manuscript. This text has also benefited from the comments of the participants of the conference on justice and economics in Toulouse, the Interface workshop in Nice, and the GREQAM seminar of economic philosophy. Of course, all errors or omissions are mine. Comments and suggestions are most welcome: muriel.gilardone@unicaen.fr. 
While it is clear that Sen draws inspiration from Rawls's work, the nature of that inspiration is paradoxical. The article seeks to clarify certain common misconceptions about the relationship between them - misconceptions that are due in no small measure to Sen himself, for Sen's comments regarding his relationship to Rawls are not always clear, and are sometimes misleading. For instance, in his autobiography (1999), Sen says that the only major influence Rawls had on him was with respect to the development of his capability approach, and he persists in presenting that approach as an extension of Rawls's theory of justice as fairness. $^{2}$ In the course of this article I will invalidate both assertions, eventually demonstrating that Sen's departure from Rawls turns less on a different metric of justice than on a divergent conception of impartiality, one which undermines the foundation of Rawls's theory of justice.

In order to understand this apparent reversal, I focus on Sen's use of Rawls's ideas, and investigate how this usage has evolved over time. ${ }^{3}$ To this end, I have made two essential methodological choices: (1) to go back to Sen's early writings on social choice theory, which mark the beginning of his dialogue with Rawls; ${ }^{4}(2)$ to avoid following Sen's famously clearcut separation between his contributions to economics and his contributions to philosophy. ${ }^{5}$ In so doing, I highlight the way in which Rawls has influenced Sen in the direction of postwelfarism, and also how some overlooked passages in otherwise well-known articles can be reread to better understand Sen's intellectual development from welfare economics to justice theory, so as to identify the points at which he departs from Rawls. In my view, this examination of Rawls's influence and counter-influence on Sen's work can provide a better understanding of the meaning and scope of Sen's contribution to the theory of justice; by the same token, it is also a means to dispute certain widely accepted ideas, particularly regarding the capability approach, which Sen is now notably less keen to advocate. Although it is

2 "If my work in social choice theory was initially motivated by a desire to overcome Arrow's pessimistic picture by going beyond his limited informational base, my work on social justice based on individual freedoms and capabilities was similarly motivated by an aspiration to learn from, but go beyond, John Rawls's elegant theory of justice, through a broader use of available information" (Sen, 1999).

3 There is a great deal more to say about Rawls's own intellectual evolution, especially in response to Sen's criticism, and regarding the important insights provided by Rawls which Sen ignores, but this is beyond the scope of this article.

4 While Robeyns (2009) has deliberately “put aside Sen's critique of Rawls's difference principle," I want to keep in focus that Rawls has been one of Sen's constant points of reference in his long-running attempt to include equity concerns in social choice theory.

5 In interview, Sen has given a clear statement of his position regarding his contributions to both fields, acknowledging, however, that they are not fully independent: "ideas from economics may have come into my [philosophical] writings, but these are not contributions that aim at "integrating" the two subjects. They are meant to be no more than some insights from economic reasoning that are relevant for philosophy. And the book The Idea of Justice is specifically a contribution to the theory of justice, not an attempt to integrate economics and philosophy." (Baujard, Gilardone, \& Salles, 2013). 
certainly not the case that Sen's ambition was, from the outset, to provide an alternative theory of justice, I shall establish by a close analysis of his use of Rawls's ideas since the late sixties that this has progressively emerged as his goal, and in a way that is not surprising once one pays due attention to Sen's critical views regarding the idea of "the original position."

The paper is organized as follows. Section 1 sets out the history of the engagement between Sen and Rawls, showing to what extent Sen has drawn on Rawls's work in the context of social choice theory. Section 2 examines Sen's rejection of the welfarist framework, and highlights a crucial misunderstanding, widely repeated in the literature, as to whether Sen's capability approach is intended as a theory of justice in the tradition that Rawls initiated. Section 3 highlights Sen's growing doubts regarding the relevance of Rawls's principles of fairness and conception of impartiality. And section 4 argues that Sen's mature writings on justice (and only those writings) can be seen intended to replace, and not just to supplement, the Rawlsian theory.

\section{Maximin/leximin versus the "difference principle"}

Sen and Rawls met in the late sixties while teaching a joint course on social justice along with Kenneth Arrow. Rawls then had a manuscript which would later become his $A$ Theory of Justice, while Sen was working on his Collective Choice and Social Welfare (Sen, 1970a, henceforth $C C S W$ ) - the ambition of the latter being to develop social choice theory in a way that would render it better able to deal with issues of justice and equality (see Baujard, Gilardone, \& Salles, 2012). Several passages of CCSW contain references to Rawls, especially the preface (p. vii), where Sen insists on the importance of ethics and especially of the theory of justice in his own approach to social choice theory. He acknowledges that Rawls "read entirely the first version of the manuscript [...] and has put me right on several questions, especially on the philosophical side of the problem" (p. viii). In a recent interview, Sen remembers the beginning of their dialogue as follows:

I benefited as much from Rawls's comments on my manuscript [...] as from reading his own book and my conversations with him. He would ask me "why do you say that? Why do you say this?" It was wonderful to argue with him.

[...] by that time, Arrow and I were parting company on the subject of interpersonal comparisons of well-being. I do not accept that interpersonal comparisons must be arbitrary, or confused. Arrow tended to think then - I think even now probably - that there's something wrong somewhere about it. By the way, John Rawls also was unsympathetic to the idea of interpersonal comparison of well-being, even though he was sympathetic to the primary goods comparison based on an index. So I differ from both in this respect. That became clear also in the seminar in 1968; I was the only 
defender of interpersonal comparisons of well-being in those classes. (Baujard, Gilardone, \& Salles, 2013)

Thinking about this debate more than forty years later, Sen acknowledges that Rawls was a defender of primary goods - rather than utility - comparisons, and thus claims that he departed from Rawls on this point. However, as I will be emphasizing, this departure was certainly not intentional, because until 1979 Sen considered it "Rawlsian" to maximize the welfare of the worst-off person - where welfare is framed in terms of utility, and not primary goods. It is nevertheless true that, in 1970, Sen tried to break the taboo against interpersonal utility comparisons that characterized both the so-called new welfare economics and social choice theory as it was conceived by Arrow. ${ }^{6}$ Sen opposes L. Robbins's attack on interpersonal comparisons (1938), ${ }^{7}$ as well as the powerful influence of positivism, particularly because they have led to a concentration on Pareto optimality ${ }^{8}$ and "the virtual elimination of distributional questions from the formal literature on welfare economics" (CCSW, p. 100). To this end, he deplores the fact that Robbins made no distinction "between some comparability and total comparability of units" (pp. 99-100) and tries to provide a rigorous presentation of a possible framework for interpersonal comparability.

In an article published in Econometrica in the same year as CCSW, Sen writes that "Judgements about social welfare are intimately connected with possibilities of interpersonal comparability of individual welfare in the usual form such judgements take" (Sen 1970b, p. 393). Here he distinguishes two kinds of interpersonal comparisons: (1) the comparison of the sums of individual welfare levels for distinct alternatives, such as under utilitarianism; (2) the comparison of the welfare levels of the "worst-off" individual in the respective social states, inspired by Rawls's criteria of justice ${ }^{9}$ (Sen 1970b, p. 393). In the first case, the "origins" of the individual welfare functions - who is concerned by this or that function make no difference, as they get subtracted out in pairwise comparisons, whereas they are

6 Recall that Arrow's theorem $(1950,1951,1963)$ excluded the possibility of interpersonal comparisons of utility.

7 In this famous article, Robbins maintains that propositions involving interpersonal comparisons of utility could not be verified by observation or introspection, and thus cannot be taken as "scientific." He draws here on Jevons's writings: "I see no means," Jevons had said, "whereby such comparison can be accomplished. Every mind is inscrutable to every other mind and no common denominator of feeling is possible" (Robbins, 1938, p. 637).

8 According to Sen (1970a, p. 57), the Pareto principle has often been taken to be "value-free" on the basis of the "implicit assumption [...] that if everyone agrees on a value judgment, then it is not a value judgment at all."

9 It is in fact inspired by Rawls's second principle of justice, as Rawls (1963) views it: it is interpreted to require that "social inequalities be arranged to make the worst-off best-off," i.e., the welfare level of the worst-off individual be made as high as possible (Sen, 1970a, p. 136). Sen adds that while "Rawls' main focus is on institutions to be chosen, [...] the maximin principle can be used also to order social states based on individual orderings" (ibid., p. 137). 
crucial in the second. In contrast, cardinal measures of individual welfare levels - welfare units - are necessary in the first case and redundant in the second as the only information needed concerns absolute levels of welfare. In this article, then, Sen remains exclusively concerned with aggregating individual welfare measures and with individual welfare units' comparability - developing a continuum of intermediate assumptions between full comparability and no comparability at all. Since his purpose is aggregation, he does not need to refer to Rawls's criteria of justice.

However, in his 1974 paper "Rawls versus Bentham: An examination of the pure distribution problem," Sen compares and contrasts the decision rules yielded respectively by what he calls the Rawlsian "maximin" conception of justice and by classical utilitarianism. The context this time is a pure distribution problem, typified by the question of how to fairly divide a cake among $n$ persons. According to Sen (1974, p. 302), the utilitarian rule (UR) is to maximize the sum of individual welfares; the simplest version of the Rawlsian maximin rule (MR) is to maximize the welfare of the worst-off person; and the lexicographic version of the Rawlsian maximin rule (LMR) is to follow MR, but if the worst-off persons in the two distributions are equally well-off, then to maximize the welfare of the second-worst-off person, and so on. ${ }^{10}$ To compare these decision rules, Sen proposes to examine them in the light of three axioms: the symmetry preference axiom, ${ }^{11}$ the weak equity axiom, ${ }^{12}$ and the joint transfer axiom. ${ }^{13}$ As Sen observes, the first one "stands in favour of a reduction of inequality if the persons have identical "needs"; the second one "demands that a person who is more deprived in non-income respects should not be made to receive less income as well"; and the third one "suggests that an inequality increasing transfer (from $k$ to $j$ ) can be outweighed by a sufficiently large inequality decreasing transfer (from $i$ to $j$ )" - trade offs are permitted (Sen 1974, p. 302). The result is that neither of the rules can satisfy all three axioms, but "choice rules do exist that satisfy all three [...] minimizing a standard measure of inequality, viz., the Gini coefficient, is such a rule" (p. 306).

In both cases - the Rawlsian maximin conception of justice and classical utilitarianism - Sen shows that some essential aspects of distributional welfare judgments are omitted:

10 This rule has been called "leximin" - "for brevity" - since Sen 1976, p. 251.

11 "If everyone has the same welfare function, then any transfer from a richer man to a poorer man, which does not reverse the inequality, is always preferable" (Sen, 1974, p. 302).

12 "If person $i$ is worse off than person $j$ whenever $i$ and $j$ have the same income level, then no less income should be given to $i$ than to $j$ in the optimal solution of the pure distribution problem" (Sen, 1974, p. 302).

13 "It is possible to specify a situation in which $j$ is [slightly] better off than $k$ (the worst-off person), and [strongly] worse off than $i$, such that some transfer from $i$ to $j$ [sufficiently large], even though combined with a simultaneous transfer [sufficiently small] from $k$ to $j$, leads to a preferred state than in the absence of the two transfers" (Sen, 1974, p. 302). 
Rawls leaves out questions of welfare differences, whereas utilitarianism leaves out questions of welfare levels. The contrast and the respective omissions can be easily seen in the light of Sen's question:

Under what circumstances should a transfer of income from person $i$ to person $j$ be recommended under the two approaches? Under UR, such a transfer should take place if and only if the welfare gain of $j$ is greater than the welfare loss of $i$ from the transfer. Under MR, it should take place if and only if $i$ has a higher level of welfare than $j$ who is the worst off person [...]. (Sen 1974, p. 308)

Sen considers that Rawls's interest in welfare levels, as opposed to the exclusive concern with marginal gains and losses of utility units, is relevant, but goes too far in that direction:

Given the powerful hold that utilitarianism has had on thinking on public policy for centuries, it is understandable, and in most ways entirely welcome, that Rawls has concentrated totally on the other half of the information set. But a more complete theory is yet to emerge. (Sen 1974, p. 308)

Sen's proposal is thus to pay attention to the ranking of welfare levels without concentrating exclusively on the welfare levels of the worst-off persons only - this being a kind of compromise between Rawls and Bentham. His weak equity axiom (WEA) is presented as "an example of a partial rule that is not extremist in the sense in which MR or LMR are, but which uses the same type of information as the Rawlsian criteria” (p. 308). Indeed, MR or LMR demand that a transfer of income should take place if person $i$ is worse off than person $j$ when $i$ and $j$ have the same income level, whereas WEA recommends that no less income should be given to $i$ than to $j$. But the last sentence of the article - "But a more complete theory is yet to emerge" - seems to presage further developments to come.

In "Welfare inequalities and Rawlsian axiomatics" (1976) Sen raises another question that makes the problem more complex: What are we supposed to aggregate? He identifies at least two possibilities: (1) individual interests, that is to say self-centered preferences; (2) judgments on what should be done, for example views on the right public policy. In the first case, Sen considers it reasonable to take leximin as a solution. Moreover, he suggests that "the contrast between giving priority to the welfare ranking of the worst off person as opposed to the welfare ranking of the person who 'gains more' $[\ldots]$ is a contrast between two alternative approaches to dealing with interest conflicts" (1976, p. 255). In a context of judgment aggregation, solutions cannot be thought of in the same way and indeed this is not a problem which leximin can sensibly address. Consequently, leximin is not a good solution to the social 
choice problem as envisaged by Arrow. ${ }^{14}$ Nevertheless, Sen comments "the criticism of utilitarianism is not thereby wiped out" (p. 259), and he recalls "Rawls' (1971) own conclusions about his theory: (i) 'it is not a fully satisfactory theory', and (ii) 'it offers... an alternative to the utilitarian view which has for so long held the pre-eminent place in our moral philosophy' (p. 586)." While Sen acknowledges that Rawls was referring here to his theory of justice as fairness in its broad form, he considers that "the observations seem to apply specifically to leximin as well" - that is, to Sen's own (re)interpretation and narrowing of Rawls's theory.

From 1977 onwards, Sen begins to develop a criticism of what he calls "welfarism," beyond utilitarianism:

The general approach of making no use of any information about the social states other than that of personal welfares generated in them may be called "welfarism". I would argue that (i) welfarism as an approach to social decisions is very restrictive, and (ii) when the information on personal welfare is itself limited, it can be positively obnoxious. (Sen, 1977, p. 1559)

According to Sen, leximin and utilitarianism are two examples of welfarist approaches, and one way of seeing their limits is in terms of their ability "to accommodate some of the general principles or values that have been widely acclaimed" (p. 1559). Sen argues that the principles of liberty and equality conflict with welfarism; but while one could refer to Rawls's theory and its two principles of justice to view how liberty and equality can be apprehended outside a welfarist approach, this is not the approach which Sen adopts. Undoubtedly, he was at this time too accustomed to interpreting Rawls's principles from the traditional welfarist perspective that then prevailed in economics. Indeed, Rawls is rarely mentioned and, when he is, it is in a notably allusive and marginal way. For example, in a footnote Sen refers to Rawls (1971) and Nozick (1973) for two alternative approaches to the issue of liberty - that is, approaches that do not justify their prior interest in liberty on welfarist grounds (Sen, 1977, p. 1560). But in order to demonstrate this, Sen adopts the approach of showing that Marx's and Nozick's systems "share a rejection of welfarism, and relate social evaluation to historical information (e.g. dated labor in the case of Marx; past savings and inheritance in the case of Nozick)" (p. 1560).

14 In Arrow's conception, individual preferences are orderings of each social state that are grounded not only on individuals' direct consumptions but also on the commodities distribution in each state. As orderings of voters can be influenced by equity standards, it is more appropriate to view them in terms of individual values rather than individual tastes. The title of his book - Collective Choices and Individual Values - is quite clear on that point; however, the difference seems not to be so sharp as far as Arrow is concerned. 
Concerning the issue of equality, ${ }^{15}$ Sen considers that this may be one of the major concerns that is best captured under welfarism, at least when the objective is to equate the welfare levels of different persons (Sen, 1977, p. 1561). But he persists in linking the name of Rawls with the leximin or maximin approach, and now proposes some powerful criticisms of the latter. First, he shows that while "[i]n a two-person conflict, the Rawlsian rule of giving priority to the interests of the worse off is appealing [...] The appeal of the Rawlsian rule may be thought to be much weaker in n-person conflicts where the interest of one may go against the interests of everyone else (perhaps a billion of them!)" (p. 1555). This is what is called in social choice theory "the Rawlsian 'dictatorship' of the worst off" - a special case of a "positionalist" dictatorship due to a combination of ordinal level comparability and the independence of irrelevant alternatives (p. 1550).

Second, even if the leximin approach was accepted - in spite of its questionable moral consequences - it is, as already mentioned, still welfarist. This interpretation of Rawls's approach thus has quite limited scope for providing an adequate treatment of equality:

If $[\ldots]$ egality is defined not in terms of welfare but some other characteristics, e.g., income, wealth, education, or treatment before the law, then welfarism may, in fact, be unable to accommodate even egality. (Sen, 1977, p. 1561)

Arguably, however, the proper target of these attacks is not so much Rawls's perspective but rather the way economists, and Sen in particular, have interpreted it within the context of social choice theory. ${ }^{16}$ It is only in 1979 that Sen starts to show a better understanding of Rawls's ideas. In "Utilitarianism and welfarism" (1979a), Sen finally acknowledges - in a footnote - that "It may be important to mention here that, although Rawls considers the claim of the minimum element of utilities as against that of total utility, his 'difference principle' focuses directly on the minimal availability of 'social primary goods' and not on minimal utility as such" (1979a, p. 465, my emphasis). However, he continues to state that egalitarian considerations of a certain sort can be accommodated "with the utility-based version of the Rawlsian difference principle" (p. 471, my emphasis). Indeed, this interpretation of Rawls's difference principle was used to replace one characteristic of what Sen calls "outcome utilitarianism," defined as a combination of welfarism and sum-

15 In fact Sen (1977, p. 1561) calls it the issue of "egality."

16 Notice that the tendency to criticize Rawls's ideas from a welfarist angle is not peculiar to Sen; see, for example, Arrow 1973 and Harsanyi 1975. However, as we have seen in section 1, Sen is the first to have established a parallel between the difference principle and the social choice problem. For a discussion of the interpretation of the Rawlsian theory of justice by economists in the seventies, see Peter 2008, pp. 444-449. 
ranking. Sum-ranking means that "one collection of utilities is at least as good as another if and only if it has at least as large a sum total" and it is obviously "insensitive to the inequality of utilities" (p. 468). The "Rawlsian leximin" can thus be seen as a response to this utilitarian insensitiveness to inequality, although its nature is not fully satisfactory.

In "Personal utilities and public judgements: Or what's wrong with welfare economics" (1979b), ${ }^{17}$ Sen clarifies and summarizes many of the ideas he had been exploring for a decade. First, he evokes ordinal utility comparisons, like "Rawls's (1971) 'maximin' interpreted in terms of utilities," as a way out of Arrow's impossibility theorem (Sen, 1979b, p. 546). But, he stresses, "[t]his makes the 'worst off rank' something like a dictator, and though it is not a personal dictatorship, it is possible to argue that it is a rather extreme approach." Second, he argues that "some moral principles are formulated without making any use of utility information at all, e.g. 'equal pay for equal work', 'non exploitation', etc. and it is easy to demonstrate that these principles would conflict with welfarism" (Sen, 1979b, p. 548). Among these non-welfarist principles, Sen this time ranks Rawls's difference principle:

Even Rawls' (1971) 'difference principle' in his theory of justice, in which a person's disadvantage is judged in terms of his access to 'primary social goods', and not in terms of utility as such (as in the apocryphal version popular among economists), will clash violently with welfarism. (Sen, 1979b, p. 548, my emphasis)

Third, among the many ways of avoiding the impasse of social choice theory, "dropping welfarism is one, using a richer utility information is another" (p. 554). Prior to this article, Sen had confined himself to an exploration of the second possibility by distinguishing the poor from the rich and attempting to give priority to the interests of the former; ${ }^{18}$ here however he seems to militate for a radical departure from welfarism:

[Welfarism] remains a very limiting constraint even when the utility information is very rich [...]. This can be brought out by explicitly considering such issues as liberty, discrimination, exploitation, or entitlement to social security. The underlying principles tend to give non-utility information a role of its own (in addition to any relevance it might have as determinant of - or as surrogate for - utility data). (Sen, 1979b, p. 554)

17 In this article Sen thanks Rawls as well as Kenneth Arrow and Maurice Dobb "for stimulating discussions over a great many years on the subject [...]" (Sen, 1979b, p. 537).

18 In particular, Sen shows that Arrow's (1951) axiom makes it impossible to aggregate the conflicting interests of the poor and the rich by giving priority to the interests of the poor - as it is not possible to identify him either in terms of utility or non-utility information. Furthermore, Sen takes for granted Arrow's intent to consider values and not tastes, by taking orderings as judgments rather than interests. 
Here we may note that Sen's criticism of welfarism does not come from his reading of Rawls - as his welfarist exploration of the difference principle attests - but rather from his exploration of Arrow's axiomatization with the intention of saying something about justice. His Tanner lecture of May 1979 - entitled "Equality of what?" (Sen, 1980) - will turn out to be the first time that Sen proposes a non-welfarist approach of interpersonal comparability. And in this context, I shall now argue, he thus opens a real discussion with Rawls, based on a more faithful reading of his criticism of utilitarianism.

\section{2. "Basic capabilities" versus "primary social goods"}

In his first Tanner lecture, Sen examines three particular types - or so-called types - of equality: utilitarian equality, total utility equality, and Rawlsian equality. The originality of this lecture, as compared to his previous articles, consists in his demonstration that

all three have serious limitations, and that while they fail in rather different and contrasting ways, an adequate theory cannot be constructed even on the combined grounds of the three. [...] I shall try to present an alternative formulation of equality which seems to me to deserve a good deal more attention than it has received, and I shall not desist from doing some propaganda on its behalf. (Sen, 1980, p. 197).

Sen no longer thinks that a good way to assess equality would be a kind of compromise between the Rawlsian and the utilitarian perspectives - for example, paying attention to the ranking of welfare levels without concentrating exclusively on the welfare levels of the worst-off persons only - as he did in his 1974 article. Indeed, Sen leaves out the "weak equity axiom" he had tried to deploy in that context. Moreover, he no longer defines maximin as a Rawlsian criterion, and presents it instead as a conventional alternative to utilitarianism as used in social choice theory in a context of total utility equality: ${ }^{19}$

Another distinguished case is the criterion of judging the goodness of a state by the utility level of the worst-off person in that state - a criterion often attributed to John Rawls. (Except by John Rawls! He uses social primary goods rather than utility as the index of advantage, as we shall presently discuss.) One can also take some other function of the utilities - other than the sum-total or the minimal element. (Sen, 1980, p. 205, my emphasis)

19 The choice here is between two cases of non-equal distributions with total utility being the same in each case - i.e., there is total utility equality. It appears that something more has to be said such that they could be ranked in a way that incorporates equity standards. 
In fact, as seen earlier, maximin is often not enough to reach a strict and complete ranking of social states, and the lexicographic version of the maximin rule, leximin, is much more common in social choice theory. Sen dwells on its questionable implications:

Just as utilitarianism pays no attention to the force of one's claim arising from one's disadvantage, leximin ignores claims arising from the intensity of one's needs. The ordinal characteristic that was pointed out while presenting the axiom of utility equality preference makes the approach insensitive to the magnitudes of potential utility gains and losses. (Sen, 1980, p. 208)

Aside from its indifference to "how much?" questions, i.e., the intensity of needs, Sen reminds us that leximin also has little interest in "how many?" questions - paying no attention at all to the number of people whose interests are overridden in the pursuit of the interests of the worst off. Again, he points out the problem of the exclusive concern with utility data that makes both utilitarianism and leximin inadequate responses to the question of equality. As the problem is now identified as welfarism in both approaches, it is quite natural to dismiss the idea of a combination of the two in pursuit of a better approach - even if they differ sharply in their respective use of utility information.

Sen then pursues his account of what is wrong with welfarism. To this end, he now makes an important use of Rawls's arguments in order to expose the limits of this general and common approach to equality judgments, acknowledging the strength of Rawls's "critiques in terms of liberty and equality" (Sen, 1980, p. 201), and quoting at length Rawls's explanation of why utilitarianism is not a good approach to justice in order to reveal one aspect of the shortcomings of welfarism:

In calculating the greatest balance of satisfaction it does not matter, except indirectly, what the desires are for. We are to arrange institutions so as to obtain the greatest sum of satisfactions; we ask no questions about their source or quality but only how their satisfaction would affect the total of well-being. . . Thus if men take a certain pleasure in discriminating against one another, in subjecting others to a lesser liberty as a means of enhancing their self-respect, then the satisfaction of these desires must be weighed in our deliberations according to their intensity, or whatever, along with other desires. . . . In justice as fairness, on the other hand, persons accept in advance a principle of equal liberty and they do this without a knowledge of their more particular ends. . . . An individual who finds that he enjoys seeing others in positions of lesser liberty understands that he has no claim whatever to this enjoyment. The pleasure he takes in other's deprivation is wrong in itself: it is a satisfaction which requires the violation of a principle to which he would agree in the original position. (Rawls 1971, pp. 30-31; quoted by Sen 1980, pp. 210-11, my emphasis) 
What is at stake in this attack of welfarism, and a fortiori utilitarianism, is "the lack of 'parity' between one source of utility and another." ${ }^{20}$ Indeed:

Welfarism requires the endorsement not merely of the widely shared intuition that any pleasure has some value - and one would have to be a bit of a kill-joy to dissent from this - but also the much more dubious proposition that pleasures must be relatively weighed only according to their respective intensities, irrespective of the source of the pleasure and the nature of the activity that goes with it. (Sen, 1980, p. 211, my emphasis)

And, for the first time, Sen examines Rawls's (1971, pp. 60-65) proposal to focus on "primary social goods" rather than utility:

These are "things that every rational man is presumed to want," including "rights, liberties and opportunities, income and wealth, and the social bases of self-respect." $[\ldots]$

Since advantage is judged not in terms of utilities at all, but through the index of primary goods, expensive tastes cease to provide a ground for getting more income. Rawls justifies this in terms of a person's responsibility for his own ends. (Sen, 1980, pp. 214-215)

For Sen, Rawls's conception of individual advantage has the virtue of escaping from one particular difficulty with welfarism: as objective criteria of well-being can be directly accommodated within the index of primary goods, the problem of parity between pleasures from different sources no longer gives rise to bias in judgments. Indeed, the question of pleasures is out of the framework, since what counts is the source of pleasure, and they "can be discriminated on the basis of the nature of the goods" (Sen, 1980, p. 214). In this context, leximin can be applied without being open to the criticism that it gives priority - i.e., more income - to "people who are hard to please and who have to be deluged in champagne and buried in caviar to bring them to a normal level of utility, which you and I get from a sandwich and beer" (p. 214). Consequently, the important advance of Rawls's index of primary social goods is that it avoids the dependence on tastes and subjective features, making room for responsibility towards each individual's own ends. Judgments of well-being and equality can now be based on certain objective factors, like being or not being hungry, cold, or oppressed.

20 The term "parity" is borrowed from John Stuart Mill (1859 [1863], p. 162): "there is no parity between the feeling of a person for his own opinion, and the feeling of another who is offended at his holding it; no more than between the desire of a thief to take a purse, and the desire of the right owner to keep it. And a person's taste is as much his own peculiar concern as his opinion or his purse." 
However, while Sen acknowledges the merits of Rawls's approach of individual advantage, he also notes one major drawback:

If people were basically very similar, then an index of primary goods might be quite a good way of judging advantage. But, in fact, people seem to have very different needs varying with health, longevity, climatic conditions, location, work conditions, temperament, and even body size (affecting food and clothing requirements). So what is involved is not merely ignoring a few hard cases, but overlooking very widespread and real differences. Judging advantage purely in terms of primary goods leads to a partially blind morality. (Sen, 1980, pp. 215-216, my emphasis) ${ }^{21}$

Sen criticizes Rawls for his indifference to "hard cases" - disabilities, special health needs, physical or mental defects - which he had justified on the pretext that they "distract our moral perception by leading us to think of people distant from us whose fate arouses pity and anxiety" (Rawls, 1975, p. 86; quoted by Sen, 1980, p. 215). For Sen, not only does this attitude amount to stating that such cases have no moral relevance at all, ${ }^{22}$ but the problem is also much more widespread than Rawls tends to think, because of human diversity. In the same way as utilitarianism loses its normative appeal for distribution questions because of its unrealistic hypothesis of identical individual utility functions, Rawls's theory of justice is far less appealing since it is intended for people with identical needs. ${ }^{23}$ This leads Sen to go yet further in his criticism of Rawls's conception of individual advantage, ending up accusing Rawls of "fetishism":

there is, in fact, an element of "fetishism" in the Rawlsian framework. Rawls takes primary goods as the embodiment of advantage, rather than taking advantage to be a relationship between persons and goods. Utilitarianism, or leximin, or - more generally - welfarism does not have this fetishism, since utilities are reflections of one type of relation between persons and goods. (Sen, 1980, p. 216, my emphasis)

Interestingly, Sen seems to be less categorical than Rawls in his rejection of welfarism. He underlines welfarism's insufficiency, but does not consider this approach as totally irrelevant. For him, Rawls has gone too far in the opposite direction to welfarism and fails to consider crucial information such as the absence of exploitation or discrimination, or

21 Sen here contradicts what he wrote in $\operatorname{CCSW}$ (p. 98, n. 18): "[It] is not easy to [give special consideration to handicapped people whose enjoyment measure may be thought to be uniformly lower] in the utilitarian framework, but it is important in other approaches, e.g., in Rawls' theory of justice."

22 It might be noted that Sen's violent attack against Rawls here is toned down in the reprint of "Equality of what?" in Sen 1982b. Indeed, he adds a footnote to apologize for the possibly misleading character of his suggestion: in fact, Rawls proposes to postpone the question of hard cases, and not to ignore it. Nevertheless, he persists in saying that the question cannot be postponed and must be included in a theory of justice like the one Rawls is proposing (Sen, 1982b, pp. 365-366).

23 Arrow (1973) had already pointed out this failure of Rawls' theory of justice as fairness. 
even people's unequal needs. Instead, Sen (p. 218) now proposes a theory based on "basic capabilities," defined as "a person being able to do certain basic things" like "the ability to meet one's nutritional requirements, the wherewithal to be clothed and sheltered, the power to participate in the social life of the community." He justifies this new informational basis by its capacity to capture a notion of urgency and directly integrate "hard cases" into the analysis, in contrast to welfarism or the primary social goods approach:

If it is argued that resources should be devoted to remove or substantially reduce the handicap of the cripple despite there being no marginal utility argument (because it is expensive), despite there being no total utility argument (because he is so contented), and despite there being no primary goods deprivation (because he has the goods that others have), the case must rest on something else. I believe what is at issue is the interpretation of needs in the form of basic capabilities. (Sen, 1980, p. 218)

While it is necessary for Sen to ground equality judgments on objective criteria, social primary goods are too good-centered and say nothing concerning what liberty they offer to human beings. Meanwhile, utility focuses too much on "the psychological side of the story," to the neglect of "non-psychological effects of goods on people" such as malnutrition (Sen, 1982, p. 30). According to Sen, what Rawls was aiming at by proposing his index of social primary goods would be better served by referring to people's basic capabilities: he erred by focusing "on income rather than on what income does, on the 'social bases of self-respect' rather than on self-respect itself, and so on" (Sen, 1980, p. 219). Consequently Sen's first presentation of his capability approach is indeed responsible, at root, for the fact that it has been interpreted as an extension of the Rawlsian approach of justice: "The focus on basic capabilities can be seen as a natural extension of Rawls's concern with primary goods, shifting attention from goods to what goods do to human beings" (Sen, 1980, pp. 218-219, my emphasis).

This part of the article is well known. However, Sen also admits that the choice of a new conception of individual advantage for equality evaluations - "for that part of it which is concerned with needs rather than deserts" (p. 220) - does not fully resolve the problem, and indeed that he views it as only "a partial guide to the part of moral goodness that is associated with the idea of equality" (p. 220). First, there still exists "the problem of indexing the basic capability bundles," which is, "in many ways, comparable with the indexing of primary good bundles in the context of Rawlsian equality" (p. 219). Second, there is the issue of weighting the different capabilities within the index. Third, an index of basic capabilities provides a dimension to focus on; it still remains to define a decision rule like leximin, the utilitarian rule 
or the weak equity axiom for the utility dimension or Rawls's difference principle for the primary social goods index. In this regard, Sen seems to be open to various applications:

Basic capability equality corresponds to total utility equality, and it can be extended in different directions, eg., to leximin of basic capabilities. On the other hand, the index can be used also in a way similar to utilitarianism, judging the strength of a claim in terms of incremental contribution to enhancing the index value. (Sen, 1980, p. 220)

Fourth, "basic capability equality" is not considered by Sen to be "the sole guide to the moral good," as there could be other morally relevant claims to take into account for equality judgments, but also in other types of moral judgments of social states. The important innovation constituted by the basic capability dimension has largely overshadowed this qualificatory statement. Indeed, this last point has often been left out by commentators, which explains why some have seen Sen as having reversed his position on the capability approach, as he himself emphasized in a later interview:

I have to rescue myself by saying I'm not a capability theorist [...] I have great interest in capability, I am proud that I had a role in leading the discussion on this in contemporary political philosophy, but I don't think you can have a theory of justice based on capability only, there is no way. Capability analysis can be an important part of a bigger story. (Baujard, Gilardone, \& Salles, 2013)

To deal with the first two problems just listed - the capabilities indexing and weighting - Sen suggests that Rawls's approach to justice is a good avenue to explore, but only by replacing primary social goods by basic capabilities:

While Rawlsian equality has the characteristic of being both culture-dependent and fetishist, basic capability equality avoids fetishism, but remains culture-dependent. Indeed, basic capability equality can be seen as essentially an extension of the Rawlsian approach in a non-fetishist direction. (Sen, 1980, p. 219)

In fact this suggestion seems to contradict other parts of the article, and indeed is, in my view, the source of many misunderstandings regarding Sen's own approach to justice, which is obviously distinct from Rawls's. In the next section, I explain further how these two sentences have had the effect of creating ungrounded expectations that Sen's development of his capability approach would be a true replacement for Rawls's theory of justice as fairness providing aggregative or prescriptive principles and a clear view of what should be in the capability bundles. To this end, I highlight the ways in which his lecture "Equality of what?" represents the beginning of another major transformation in Sen's position vis-à-vis Rawls, specifically regarding the relevance of Rawls's fundamental principle of fairness. 


\section{3. "Positional objectivity" versus "the original position"}

To understand why Sen misleads us when he suggests that his approach "can be seen as essentially an extension of the Rawlsian approach," it is worth studying his skeptical position as regards Rawls's procedure for justifying his theory of justice - be it in the choice of primary social goods instead of the utility dimension, or the choice of justice principles. While Sen agrees with Rawls's rejection of "the welfarist no-nonsense counting of utility irrespective of all other information" (Sen, 1980, p. 211), he disagrees with Rawls's way of doing it. As evident in the passage previously cited, Rawls vindicates his rejection of welfarism by reference to its non-acceptability in "the original position" (1971, pp. 30-31; cited on p. 10 of this paper): in that position, "persons accept in advance a principle of equal liberty and they do this without a knowledge of their more particular ends" - thus, for example, a pleasure taken from another's deprivation would be considered as wrong in itself, which is not the case within a welfarist perspective.

Sen is skeptical about whether the device of "the original position" can be used to define the principles of justice or identify the dimension on which to assess individual advantage, citing a lack of certainty about what its implications are and its lack of realism.

I must confess that I find the lure of the "original position" distinctly resistible since it seems very unclear what precisely would be chosen in such a situation. It is also far from obvious that prudential choice under $a$ s if uncertainty provides an adequate basis for moral judgment in unoriginal, i.e., real-life, positions. (Sen, 1980, p. 201)

According to Sen, in "real-life" positions, people would easily be able to spot the problem of welfarism, simply by appeal to another prior principle such as "the irreducible value of liberty" (p. 211). Moreover, he emphasizes that authors have derived very different conclusions starting out from "the original position," such as utilitarianism in John Harsanyi's work, and the radically different approach of Rawls's Justice as Fairness.

Rawls (1971) does indeed use the same device as the contemporary utilitarian Harsanyi to find which principles of justice should be chosen: namely, a hypothetical situation in which the so-called "veil of ignorance" deprives individuals of "certain morally irrelevant information" such as "their place in society, their class position or social status, their place in the distribution of natural assets and abilities, their deeper aims and interests, or their particular psychological makeup" (Rawls, 1974, p. 141). But, unlike Harsanyi, ${ }^{24}$ Rawls does 
not think that in the postulated situation, the as if ignorant people would choose the principle that average utility is to be maximized. Not only would utility be dismissed for not being a morally relevant dimension, but the maximization rule would not be considered to hold. And yet Rawls considers that everyone in the original position will reason in the same way: "Any agreement reached is unanimous and there is no need to vote" (Rawls, 1974, p. 141, my emphasis). In this context, "two principles that express a democratic idea of justice" would emerge:

1. Each person has an equal right to the most extensive scheme of equal basic liberties compatible with a similar scheme of liberties for all.

2. Social and economic inequalities are to meet two conditions: they must be (a) to the greatest expected benefit of the least advantaged members of society (the maximin equity criterion) and (b) attached to offices and positions open to all under conditions of fair equality of opportunity. (Rawls, 1974, p. 141)

The fact that Harsanyi and Rawls end up with such radically distinct perspectives from virtually identical points of departure is, for Sen, a sign that something is wrong. To say the least, Rawls's belief that there would be unanimous agreement when people are put in "the original position" is obviously questionable - if it is conceivable at all. This argument is not new. Sen had already doubted that maximin would necessarily be chosen in the original position:

Even if one rejects the criterion of maximizing expected utility [...], there are other criteria that must be considered. The pessimism-optimism index of Hurwicz (1951), of which the maximin rule is an extreme case (corresponding to a degree of pessimism equal to 1), is a possibility that can be explored, after suitable generalization. To choose one particular rule, viz., maximin, out of many may be appropriate some time, but to claim that it must be chosen by rational individuals in the "original position" seems to be a rather severe assumption. (Sen 1970a, p. 140)

The novelty concerns his perception of the original position as such. Sen has changed his mind concerning the relevance of Rawls's principle of fairness - a principle that he used to consider to be "more fundamental than his principles of justice" (Sen 1970a, p. 140). While Sen had thought it would be "possible to accept Rawls's criteria of fairness without committing oneself fully to his identification of justice" (p. 140), a decade later he refuses to engage in "the original position" and considers it necessary to call on other principles related

that "the cardinal utility concept of welfare economics [is] very close to the cardinal utility concept used in the theory of choices involving risk." Consequently, he concludes that a rational and morally acceptable social welfare function must be built on the principle of the maximization of average utility. See Harsanyi 1955, 1975, 1977. 
to what people actually experience in specific real positions. Indeed, in his Tanner lecture, he suggests that the preferences of individuals, in real-life positions, could serve as a basis from which to reach a partial ordering in case of "broad uniformity," while "supplemented by certain established conventions of relative importance" (Sen, 1980, p. 219). This social choice approach is envisaged for the selection of the basic capabilities to put into the index, "but any application of it must be rather culture-dependent, especially in the weighting of different capabilities" (p. 219). This was one of Sen's first - and, at this stage, rather vague - attempts to define how objectivity should be envisaged for justice matters.

Interestingly, in the eighties, and even more so in the nineties, Sen developed an original account of what objectivity is with respect to social evaluations. While it is usual in normative economics, or in moral philosophy, to refer to an impartial observer for global judgments on a society, Sen considers the evaluator as an individual rooted in a society and a culture, and influenced by his specific position. In no case can impartiality be understood as "neutrality" or "a conception of the world from nowhere" - to use an expression of Nagel (1980, p. 115) that Sen often cites. ${ }^{25}$ On the contrary, it would be arbitrary, and not impartial, to assess an individual situation or a social state by excluding from the outset agent-relative judgments.

Surprisingly, in his first writings on objectivity, Sen (1982a, 1983) does not directly address Rawls's perspective. Rather, he takes a stance in a debate with Williams (1973), Nozick (1973), and Nagel (1980) who, for diverse reasons, criticize consequentialist ethics for not taking agent-relative values into account. In this context, Sen (1982a, p. 33) claims that there is a "possibility of using consequence-based evaluation combined with an evaluatorrelative outcome morality [and so] distinguishing that package from consequentialism." He engages with the three authors' different arguments, which are all intended to prove that "[c]onsequentialism cannot [...] make much room for agent relative action judgements associated with deontology, tie aims, aimed tie respect, and integrity responsibility" (p. 31).

Sen also takes this opportunity to discuss the possibility of diverse valuations of social states within a single moral theory and, thus, the assumption that moral principles should emerge from unanimous agreements:

It is easy to entertain the suspicion that an evaluator-relative outcome morality must be an internally contradictory one: how can $i$ and $j$ morally value a given state $x$ differently

25 In May 1979, Thomas Nagel was also invited to deliver the Tanner Lectures and chose to present ideas on "The limits of objectivity." They were published in the same volume as Sen's "Equality of what?" Nagel's The View from Nowhere was published in 1986. 
within one consistent moral theory? The inadmissibility of evaluator relativity within one moral theory can be based on two propositions:

1. Interpersonal differences of moral valuations of the same states must indicate contradictory moral beliefs;

2. No moral theory should endorse the holding of contradictory moral beliefs. (Sen 1982a, p. 33)

Concerning point 2 , Sen does not deny that evaluator-relativity involves contradictory beliefs, and for that reason, needs to be disputed in a fruitful way. Concerning point 1 , he proposes an interpretation of interpersonal differences of moral valuation that is quite different from a contradiction in moral beliefs. Indeed, he explores "the possibility that they are coherently interpretable as 'positional' statements, reflecting the view of the state from the position of the evaluator" (p. 35). Hence, he tries to shift the discussion of evaluator-relative judgments out of the "objective-subjective dichotomy." Considering evaluator-relativity as deriving from the "positional interpretation" implies admitting "position relativity," which, in turn, "entails evaluator relativity only to the extent that evaluators differ from each other in their respective positions" and not "by virtue of their being different evaluators" (p. 36).

While Sen proposes a positional interpretation of evaluator judgment, he nevertheless admits "the substantive possibility that some things may be valuable or disvaluable from every position (starvation or acute suffering no matter to whom it occurs, for example, being a moral disvalue for every evaluator)" (p. 37). However, what is important to him in acknowledging the positional interpretation of every moral judgment is that it "permits categories of moral thoughts not admissible in more traditional formats" (p. 37), but he does not yet grasp the potential scope of this proposition.

His Strorr Lectures on objectivity at Yale University in September 1990 were an opportunity to define more precisely what he understands by "positional objectivity":

What we can observe depends on our position vis-à-vis the objects of observation. What we decide to believe is influenced by what we observe. How we decide to act relates to our beliefs. Positionally dependent observations, beliefs, and actions are central to our knowledge and practical reason. (Sen, 1993, p. 126). ${ }^{26}$

This "parametric dependence of observation" is, according to Sen, essential to the nature of objectivity in epistemology, decision theory, and ethics, and has some far-reaching consequences as regards questioning "the tradition of seeing objectivity in the form of invariance with respect to individual observers and their positions" (1993, p. 126). While

26 In 1993 Sen published an article based on the Storr lectures in Philosophy and Public Affairs, just as he did with his earlier reflections on evaluator relativity (Sen, 1982a, 1983). 
Rawls's name does not appear at all in Sen's 1993 article, my reading is that it aims indirectly at criticizing Rawls's conception of impartiality in the form of judgments from "the original position." Indeed, this conception of impartiality perfectly suits Nagel's way of defining a "view from nowhere" that corresponds, for Sen, to the positional and individual invariance tradition:

A view or form of thought is more objective than another if it relies less on the specifics of the individual's makeup and position in the world, or on the character of the particular type of creature he is. (Nagel, 1986, p. 5; quoted by Sen, 1993, pp. 126-127)

Nagel's definition amounts in fact to the same idea that lies behind Rawls's "veil of ignorance." For that reason, we can fairly consider that Sen's criticism of the view from nowhere holds also for the original position. Indeed, Sen highlights the tension between that conception of objectivity and "the inescapable positionality of observations" (1993, p. 127). The difficulty of Sen's perspective is due to the apparent contradiction that arises when he uses the expression "positional objectivity," or in the idea of taking into account culture for objective assessments. I shall first argue that, in Sen's view, positionality is very different from subjectivity; and, second, that in his view taking culture into account does not lead to cultural relativism.

Concerning the first point - that positionality is not subjectivity - Sen considers that objectivity would be better defined as a "view from a delineated somewhere" (1993, p. 127) but a "view of no one in particular" (p. 129), rather than a "view from nowhere." This suggests that objectivity has to be "both position-dependent and person-invariant":

Objectivity may require interpersonal invariance when the observation position is fixed, but that requirement is quite compatible with position-relativity of observations. (Sen, 1993, p. 127)

According to this definition, it is possible to determine whether an observation or a judgment is objective by checking "whether such an observation could be reproduced by others if placed in a similar position" (p. 127). In this sense, positionality concerns the parametric data of every observation, whereas subjectivity is clearly a challenge to objectivity. Among the different types of positional parameters that are not quirks of mental attitudes or psychology, and which can be shared by different individuals, Sen mentions "any condition that (1) may influence observation, and (2) can apply to different persons"; this includes "being myopic or color-blind or having normal eyesight; knowing or not knowing a specific language; having or not having knowledge of particular concepts; being able or not 
able to count" (p. 127). The difficulty here is to bring out the relevant positional parameters that influence an observation or a judgment in a decisive way.

Consequently, Sen seems to believe in the determinist idea that any individual observation can be entirely explained by an adequate specification of the positional parameters vis-à-vis the observed object. In other terms, if every parameter were to be revealed, then the observation should be fully understandable by anyone, and thus in a sense objectivized. This point leads us to the second distinction that has to be made to avoid a potential misunderstanding of Sen's conception of objectivity: that taking culture into account does not entail cultural relativism. Culture is part of the parameters that have to be brought out and in no case can fully express an individual's position. The demand that every parameter has to be revealed to objectivize an observation theoretically removes any suspicion of cultural relativism. The problem, of which Sen is conscious, relates to the difficulty of laying out all the parameters, such that this often results in mention of only one or two parameters - frequently, the fact of belonging to a particular society or culture - which is clearly insufficient. To illustrate his idea that culturally influenced readings of social phenomena, when exclusive, are misleading, Sen draws an example from gender studies:

belief in women's inferiority in particular skills may be statistically associated with living in a society that partly or wholly reserves those skilled occupations for men, giving little opportunity for women to establish their ability to perform these jobs. Let us call such a society an $S^{*}$ society. Is this belief $[\ldots]$ objective from the position of members of that $\mathrm{S}^{*}$ society [...]? (Sen, 1993, pp. 138-140)

Answering yes to this question would demand that we ignore other positional parameters - such as knowledge of what happens in other societies - and consider the society as a whole, disregarding internal criticism, and taking as a uniform viewpoint something that is in fact "the establishment view or the majority opinion" (p. 140). To deny the objectivity of such a belief in women's inferiority, Sen considers that we have to (1) acknowledge the underspecified character of the position "living in society $S^{*}$," and (2) not take the dominant viewpoint as the only one in society $\mathrm{S}^{*}$. Sen notes that internal criticisms from skeptics or dissenters always carry more weight than "alien critique," even if they are influenced by foreign authors (pp. 139-140).

Sen's demonstration is thus that judgments are unavoidably "position-based," which is quite different from mere subjectivity or cultural relativism. While this is a critical point to acknowledge, it does not mean that scientific reasoning has to be based on one position only. On the contrary, Sen pleads for what he calls "trans-positional assessment - drawing on but 
going beyond different positional observations" (1993, p. 130). He claims that there is a "need for comparing and assessing different points of view, diverse observations, and distinct conclusions in any given society" that "cannot be eliminated by the dubious assumption of dissentless uniformity [...] or the majority opinion" (p. 140). A "trans-positional" scrutiny would certainly "demand some kind of coherence between different positional views," but it "can lead to a broader understanding that makes sense of the respective (and possibly divergent) positional observations" (p. 140). To clarify this last point, Sen appeals to the Marxist notion of "objective illusion." This notion is "related to beliefs that are formed on the basis of a limited class of positional observations [...] [and] - false as they may be - could nevertheless have been derived objectively in the absence of access to other positional scrutiny" (p. 133). For his purposes, Sen applies it to interpret systematic illusions and persistent misunderstandings in a context of gender - and not class - inequality analysis. The "shared tendency" by men and women "not to notice the systematic deprivation of females vis-à-vis males" and the fact that "inequalities within the family tend to survive by making allies out of the deprived" is, for Sen (p. 136), a typical case of objective illusion that has to be brought to light by a trans-positional assessment. However, the evaluator, or the "scientist," is also influenced by his or her own positional features. Indeed, there is no way to escape the fact that "the observer and the observed both belong to the world in which we live, and so do the observations themselves" (p. 129). In other words, objective assessments cannot be detached from the reflexive observations of the observer or the observed. In contrast with Rawls's concept of the original position, Sen's concept of "positional objectivity" is grounded on actual judgments and beliefs, and seeks to highlight the positional parameters that influence them. But Sen is not very clear concerning the scope he wants to give to this concept, even while he suggests that it has far-reaching consequences for epistemology, decision theory, and ethics. My reading is that it is an indirect criticism of Rawls's conception of fairness and impartiality. It can be inferred from Sen's philosophical writings on objectivity that fairness would better be defined as trans-positionality. ${ }^{27}$ The idea is not to rule out value or interests conflicts, but to leave room for responsibility or duty towards others, particularly those who are worse off.

27 It can also be argued that Sen's conceptual proposition presents an indirect criticism of social choice theory, i.e., of the standard definition of preferences as fixed and undisputable judgments. Indeed the concept of "positional objectivity" is in fact a theoretical approach to individual judgments that makes sense only in a context of deliberation, so that I consider it an implicit attempt to include the issue of public reasoning and deliberation in social choice theory by offering an alternative assumption to fixed preferences. I elaborate on this issue in another paper (Gilardone, Baujard, 2012). 
Consequently, the ability to reason "trans-positionally," and not "from nowhere" or "from the original position," depends greatly on the aptitude both to invoke "rival concepts and competing lines of construction" (p. 130) and make them "positionally objective by some appropriately thorough specification of positional parameters" (p. 136). Through the deliberation process, some views could appear to be "objective illusions," while others would seem more appropriate for considering in the situation. In my view, then, Sen's writings on "positional objectivity" have two significant implications: (1) that the very notion of individual advantage and the conception of the good is formed or better understood through public discussion; and (2) that all doctrines that exist in a society must be publically discussed and clarified. This is an important contrast with Rawls, who considers that neither actual preferences related to individual advantages and present position in society, nor "unreasonable doctrines," must enter the "public political forum." 28

\section{A comparative approach to justice versus a contractual theory of justice}

Not only did the debate between Sen and Rawls not start with the article "Equality of what?," but what is at stake in this debate goes further than the mere nature of individuals' advantage - "the metric of justice" as Robeyns and Brighouse (2010) call it - or whether there must be pre-established prescriptive principles for the distribution of those advantages. ${ }^{29}$ It can indeed be difficult to understand why Sen deliberately left his theory underspecified, and thus never proposed a real alternative to Rawls's theory of justice, as many commentators were expecting him to do. In contrast, for instance, Martha Nussbaum has developed what could be seen as an alternative theory of justice in terms of a universal list of capabilities, and it has become common to interpret the difference between Nussbaum and Sen with regard to their respective specialty domains. Nussbaum's capability approach has roots in Aristotelian philosophy and the search for the nature of the "good life," whereas Sen's work is rooted in normative economics, and more precisely in social choice theory - a fact which has been thought to explain why he focuses on the appropriate procedure for drawing up a list of capabilities, rather than on the actual list itself. Sen's ambition was above all supposed to be an attempt to evolve orthodox economic theory by redefining its concepts, broadening its

28 On Rawls's ideas concerning “public reason,” see Peter, 2007, pp. 134-136 and 2009, pp. 438-439.

29 Contrary to what some commentators have asserted - such as, for example, Pellé (2006, p. 2), who asserts: "the main difference between Sen and Rawls lies in the different purpose their theor[ies] are built for. Sen's focus is on the notion of the advantage, or the opportunity of people. His main concern is to evaluate advantage or well-being of people and not to construct [a] theory of justice which implies a principle that can rule the way in which resources, understood in a very broad sense, are divided into members of a community." 
methods, and shifting its object from utility to capability, and in no sense as an attempt to replace Rawls's theory of justice as fairness. But his last book clearly contradicts this common interpretation, as does Sen's own claim that he is not a "capability theorist."

The Idea of Justice - with its dedication "in memory of John Rawls" (Sen, 2009, p. iv) - ends the dialogue with Rawls in quite a surprising way. While Sen's readers were expecting a book that would gather together the philosophical aspects of his work and disclose his immense debt toward John Rawls, the surprising result was not exactly the book announced as in development seven years earlier (see Sen, 2002, pp. vii-viii). ${ }^{30}$ The Idea of Justice comes to offer a new perspective on and a very different interpretation of Sen's enterprise. His aim is not only to break the deadlock in which economists have found themselves ever since Arrow's monograph (1951); Sen here states that he also intends to speak to philosophers. He seeks to renew normative economics as well as political philosophy, proposing a way to comprehend justice that is different than the Rawlsian approach. ${ }^{31}$ Calling into question economic orthodoxy - especially welfarism - is not enough; Sen envisages calling philosophical orthodoxy into question too.

Sen thus comes to advocate a comparative approach that is a radical departure from a theory of justice in its accepted meaning, and according to which the moral principles are considered to be a matter of social choice that is constantly renewed. Sen thus does not claim to be presenting an approach which is complementary to Rawls's theory of justice as fairness (1971), but rather a rival one. Commentators who have confined their reading to his writings on capabilities will find this striking and surprising, especially in view of Sen's (1980) own well-known presentation of his views on justice, as discussed in section 2 of this article. But for those who know his other writings, especially those regarding objectivity on which I have just commented, it can be seen as a natural development of his views and aspirations. I now focus on two features of his idea of justice: (i) the limiting role of the capability approach and the consequent overrating of the debate on the metric of justice; and (ii) the crucial role of the definition of an impartial procedure - and the consequent underrating of the debate on the original position as a starting point.

30 In fact it seems that Sen was following Rawls's advice: to write a substantial book - no mere collection of articles - to clarify what he would count as a theory of justice. The task thus took him several years, and Sen finally dedicated The Idea of Justice to John Rawls (see Gilardone, 2010, p. 709).

31 Sen still hesitates to clearly call his approach a "theory of justice" and speaks of a "particular understanding of the theory of justice" (Sen, 2009, p. 5). The title of his book, The Idea of Justice, seems to confirm his reluctance to identify his proposal with a conventional theory of justice: complete, prescriptive and directly applicable. He seems to prefer rather an "adequate theory of normative social choice." 
Regarding point (i), it has to be acknowledged first that Sen reiterates his criticism of Rawls's way of seeing individual advantage and continues to maintain that capabilities are a better approach: "the fit between a person's holding of primary goods and the substantive freedoms that the person can in fact enjoy, can be very imperfect, [...] this problem can be addressed through focusing instead on the actual capabilities of people" (2009, p. 64). Sen picks out two significant advantages of the focus on capabilities: "First, human lives are then seen inclusively, taking note of the substantive freedoms that people enjoy [...]. There is also a second significant aspect of freedom: it makes us accountable for what we do" (p. 19). And to the extent that what we do are actions that we ourselves have chosen, Sen leaves room for responsibility, and even for "deontological demands" or duty.

However, he also reiterates and develops his reservations vis-à-vis his own account of capabilities. First, he maintains that capabilities define only one aspect of freedom and do not reveal in any adequate manner the "process aspect" of freedom (p. 295). Indeed, the evaluation of capabilities remains an evaluation of results, because capabilities represent the opportunities that citizens enjoy - their freedom of life at various levels (having enough to eat, being able to participate in social and economic life or to appear in public without shame, etc.). Consequently, the capabilities account must be completed with an evaluation of the justice of the procedures which can be employed by citizens. Sen (p. 296) illustrates this first point by giving the example of the generally higher longevity of women, in other words their relatively better capability to live a long time. This statement might be thought to warrant paying more medical attention to men's health issues, but this would violate the requirement of equity in procedures. In this respect, Sen considers that priority must be given to equality of access to healthcare and not to equality of opportunity with respect to longevity, and thus he brings to light the tensions which can arise between capabilities and the process aspect of freedom.

Secondly, there can be tensions between two aspects of freedom itself: the freedom of well-being and the freedom of action. Sen has often highlighted the superiority of the capability approach over rival approaches in terms of happiness or well-being for capturing an idea of liberty as agency - meaning choice of action, but also responsibility and obligation in that choice. However, one might wonder what Sen means by saying "[w]e have to consider both the freedom of action and the nature of the consequences and outcomes [in order] to have an adequate understanding of liberty" (2009, p. 316). This can be linked to his criticism of pure consequentialism, as briefly discussed in section 3. In other words, Sen defends a "broad consequentialism" that is coherent with his notions of "evaluator relativity" or 
"positional evaluation." He has already supported consequential evaluations that "include actions done in the consequent states of affairs and [which] decide on the right action exclusively on the basis of the values of the respective states of affairs" (1983, p. 131). ${ }^{32}$ Considering agency freedom in the light of its results could be interpreted as viewing it in terms of its consequences for the person's own well-being, but Sen insists on the possibility that other objectives could be pursued: "one does not have to be a Gandhi (or a Martin Luther King, or a Nelson Mandela, or Aung San Suu Kyi) to understand that one's objectives and priorities could stretch well beyond the narrow limits of one's own personal well-being" (2009, p. 290). However, in some cases it could be relevant to examine well-being achievements, or well-being liberties to diagnose injustice - for instance to diagnose gender inequalities when only women's choices are influenced by a sense of duty towards their family.

Thirdly, Sen points out that it will be difficult to reach complete agreement on the weighting of the various capabilities identified as important, even if one decides to focus the evaluation on only one of these two aspects $(2009$, p. 298). This is linked to the plurality of aspects that deserve attention: for instance, is it more important to evaluate the ability to read and write or to appear in public without shame? In some cases, the approach's inherent incompleteness and ambiguities will not be a problem for distinguishing situations of obvious inequality, but sometimes it will be impossible to settle on a clear evaluation. For that reason, it will sometimes be necessary to introduce other criteria.

Finally, for ethical reasons, certain forms of rival reasoning can have a role to play in the evaluation of social situations, in particular those which relate to distributional choices. Sen refers in this respect to discussions about the status of efforts and the rewards that should be associated with labor. It is indeed highly relevant for Sen to seriously consider these issues, and the underlying issue of exploitation, in a theory of justice.

For all these reasons, capabilities appear "as no more than a perspective in terms of which the advantages and disadvantages of a person can be reasonably assessed" (Sen, 2009, p. 296) - which is of course not to say that the process of making this assessment would be uncomplicated. And Sen is very conscious that this perspective is far from sufficient to constitute a theory of justice:

32 He distinguished that view from a "broad deontology" that "may accept the relevance of consequences in general, but will deny that the right action is always the one which produces the best consequent states of affairs" (Sen, 1983, p. 131). 
A theory of justice - or more generally an adequate theory of normative social choice has to be alive both to the fairness of the processes involved and to the equity and efficiency of the substantive opportunities that people can enjoy. [...] The subject of fair process and a fair deal goes beyond individuals' overall advantages into other especially procedural - concerns, and these concerns cannot be adequately addressed through concentrating only on capabilities. (Sen, 2009, p. 296)

In fact, Sen had earlier suggested that the capability perspective is relevant for dealing with Rawls's second principle of justice: “"the Difference Principle' - a principle that is particularly concerned with the distribution of advantages that different people enjoy (a consideration that Rawls tried to capture, I believe inadequately, within the confines of the accounting of 'primary goods')" (2005, pp. 156-157). This clarification explains why Sen first adopted that perspective. As I have shown in the two first sections, Sen spent more than ten years thinking about the implications and the limits of this principle through the prism of social choice theory. However, he now adds: "That does not, however, obliterate in any way the relevance of the rest of the territory of justice (related to the first principle and the first part of the second principle), in which process considerations, including liberty and procedural equity, figure" (2005, p. 157).

Turning now to point (ii) - the definition of an impartial procedure that is to adjudicate the choice of justice principles - we note that Sen is unequivocal: Rawls (as well as Dworkin, Nozick, Gautier) belongs to a tradition Sen calls "transcendental institutionalism," whereas Sen himself belongs to a tradition of "realization-focused comparative approaches." Both traditions emerged in the Enlightenment period, but differ radically as regards the styles and the objects of their reasoning. The first was pioneered by Hobbes and developed in particular by Locke, Rousseau, and Kant; the other was pursued in various ways by Smith, Condorcet, Wollstonecraft, Bentham, Marx, and J. S. Mill, among others. The first examines the nature of "the just" in order to find the perfect institutions; the other compares different social arrangements and tries to find some criteria for assessing an alternative as "less unjust" than another. The first one is pure abstraction; the other is grounded on experience and observation. While the comparative approaches to which Sen refers are considerably more modest, they are, he contends, more effective with respect to actually reducing injustice.

It must be noted that as far back as 1965 Sen, together with Runciman, provided a game-theoretic interpretation of Rousseau's "general will” and of Rawls's original position, wherein the principles of justice can be viewed as solutions to cooperative games in the original position: 
Our view of the "general will", which rather follows Rousseau's emphasis on common interests than his implication of common principles, does not offer any way of establishing principles by which some players must accept to be losers except in so far as the acceptance of rules entailing loss accords with the players' long-term interest or preference. [...] we do not extend the general will so far as to allow persons to be "forced to be free" by the criterion of any principle to which they could be supposed, if rational, to have been prepared to assent from the state of nature. (Runciman and Sen, 1965, p. 560)

Runciman and Sen raise the problem of a potential conflict between the will of all and the general will, "because of the difference between the outcome of individual strategy and of enforced collusion which arises under the conditions of the non-cooperative, non-zero-sum game"; for that reason, they consider that the general will always demands fulfillment of the conditions of Pareto optimality, "although it is not suggested thereby that Pareto optimality is a sufficient criterion of justice" (p. 557). However, in contrast to game-theoretic approaches, Rawls's notions of "fairness" and "justice" are not related to cooperative solutions to bargaining problems in actual situations with given interpersonal inequalities, but with cooperative solutions in a state of primordial equality - so that "[their] reservations about the former as interpretations of fairness and justice do not, therefore, apply to Rawls" (Sen, 1970a, p. 136).

The contract in justice as fairness is not a historical contract, but rather "a firm commitment in advance [...] between free persons who have no authority over each other" on some principles according to which "their competing claims are to be settled." They add: "That this is the essence of justice, and that the social contract (in a modified form) does provide a model for it, seems to us to be adequately demonstred by Rawls" (Runciman and Sen, 1965, p. 559). The demonstration consists in showing that the notion of "social justice" does not always correspond to the notion of the "general will," and can thus generate ambiguities in its interpretation. In this paper, Sen and Runciman consider Rawls's solution for the choice of justice principles to be appropriate, with the caveat "that it involves the assumption, which we do not ourselves wish to make, that there are no conflicts between the principles of, say, needs and deserts, except those dictated by a vested position” (p. 561).

Indeed, we have seen that Sen does not question Rawls's principle of fairness until the eighties, except regarding the principles that would emerge from it and the fact that his "main interest is not so much in the ordering of social states, $[\ldots]$ but with finding just institutions as opposed to unjust ones, which is a somewhat different problem" (Sen, 1970a, p. 140). But since "Equality of what?" Sen has gradually started to cast doubt on the relevance of this 
starting point for a theory of justice. In The Idea of Justice he extends his criticism of the original position as a starting point for an acceptable theory of justice: "there may be no reasoned agreement at all, even under strict conditions of impartiality and open-minded scrutiny (for example, as identified by Rawls in his 'original position') on the nature of the 'just society'." This means that it may not be possible to reach a reasonable agreement on a unique set of principles of justice. According to Sen, it cannot be presumed that "there is basically only one kind of impartial argument, satisfying the demands of fairness, shorn of vested interests" (2009, p. 10). Besides, this would prove to be useless if it leads to the identification of an "unavailable perfect situation that could not be transcended." In Sen's view, it is more relevant to identify feasible alternatives, and then choose among them on the basis of practical reason.

However, Sen acknowledges that Rawls himself has considerably softened and qualified his basic claim of the emergence of a unique set of principles of justice in the original position - generating a real tension within Rawls's writings over the years. Not only does Rawls note that "there are indefinitely many considerations that may be appealed to in the original position and each alternative conception of justice is favored by some consideration and disfavored by others" (2001, pp. 133-134; quoted by Sen, 2009, p. 58), but he goes on to concede that "the ideal cannot be fully attained." According to Sen, "if Rawls's second thoughts are really saying what they seem to be saying, then his earlier stage-by-stage theory of justice as fairness would have to be abandoned" (2009, p. 58). But Rawls has never explicitly abandoned his theory of justice as fairness, despite its inherent and now accepted problems. Sen has fewer scruples against ruining the foundations of Rawls's influential theory. However, this does not mean he repudiates the whole body of work to which it has given birth - and there is a good reason for that: as I have shown, a large proportion of his contributions to normative economics have been directly worked out from it. Instead, Sen suggests a "dual assessment" of Rawls's theory of justice, in a way that is both appreciative and critical:

My own inclination is to think that Rawls's original theory played a huge part in making us understand various aspects of the idea of justice, and even if that theory has to be abandoned - for which there is, I would argue, a strong case - a great deal of the enlightenment from Rawls's pioneering contribution would remain and continue to enrich political philosophy. (Sen, 2009, p. 58)

As can be seen, Sen's reflections here are not just critical of Rawls's position, but positively devastating. However, although Sen rejects the device of the original position, he 
admits that "there is some merit in summoning the ideas of John Rawls and his analysis of moral and political objectivity" (2009, p. 42). Indeed, he draws inspiration from Rawls on one point, namely that "a conception of objectivity must establish a public framework of thought sufficient for the concept of judgement to apply and for conclusions to be reached on the basis of reasons and evidence after discussion and due reflection" (Rawls, 1993, p. 110). In other words, objectivity is linked to the idea of deliberative democracy and to the concept of legitimacy, and thus appeals to the existence of a sphere of deliberation where competing lines of reasoning, diverse experiences, new information, and knowledge can be exposed and discussed concerning the specific evaluations and choices that are to be undertaken. Sen adduces another important quotation from Rawls in order to stress that individual judgments, particularly if they are to carry the concerns of justice, cannot be an entirely private affair that would be unfathomable to others: "we look at our society and our place in it objectively: we share a common standpoint along with others and do not make our judgments from a personal slant” (1971, pp. 516-517; quoted at Sen, 2009, p. 134). This point cannot but strengthen Sen's proposal that value judgments can be discussed and, in the process, evolve, allowing the positionality of such judgments to be both acknowledged and - to some degree - overcome.

However, Sen does not confine the discussion to persons who are entitled to make collective choices or engaged in social evaluation because they belong to the polity, nor to a category of "reasonable" persons. Sen departs from Rawls in urging us to consider those "outside" as admissible voices, both because of the enlightenment that their perspectives may provide for those "inside," and because they might "bear some of the consequences of decisions taken in that particular polity" (Sen 2009, p. 134). ${ }^{33}$ Furthermore, he considers that "all of us are capable of being reasonable through being open-minded about welcoming information and through reflecting on arguments coming from different quarters, along with undertaking interactive deliberations and debates on how the underlying issues should be seen" (p. 43). Sen departs again from Rawls who states clearly that deliberation concerns reasonable persons who "enter on an equal footing the public world of others and [...] are ready to offer or to accept [...] equitable terms of collaboration with them" (Rawls, 1993, p.

33 In this regard, Sen proposes to address "the issue of fairness through the device of the Smithian impartial spectator [which] allows some possibilities that are not readily available in the contractarian line of reasoning used by Rawls" (2009, p. 70). In particular, he distinguishes Rawls's “closed impartiality” from Smith's “open impartiality" and insists on the latter, arguing for the need to broaden the discussion to avoid local parochialism of values. I will not discuss this feature of Sen's theory here, because it would take us far beyond the scope of this article. However, it is important to note that Sen's recourse to Smith's impartial spectator does not mean dropping positional judgments, but rather trying to view them with the eyes of other people. In this case, positionality evolves, but remains. 
53). Sen prefers to focus "on the characterization of deliberating human beings rather than on the categorization of some "reasonable persons"' (2009, p. 44). This qualification is to be linked to Sen's defense of a "plurality of impartial reasons," considering the seeking of mutual benefits, based on symmetry and reciprocity, as one form of admissible reasoning among others. ${ }^{34}$ The aim, though, tends to coincide with Rawls's: ruling out the judgments that do not survive open and informed public debate. Nevertheless, Sen seems to be less optimistic than Rawls concerning the issue of the deliberation, allowing that there might be no consensus at the end:

When we try to assess how we should behave, and what kind of societies should be understood to be patently unjust, we have reason to listen and pay some attention to the views and suggestions of others, which might or might not lead us to revise some of our own conclusions. We also attempt, frequently enough, to make others pay some attention to our priorities and our ways of thought, and in this advocacy we sometimes succeed, while at other times we fail altogether. (Sen, 2009, p. 88)

The possibility of choice, whether individual or collective, ${ }^{35}$ exists only on the basis of this kind of deliberation, and with an acknowledgement of conflicts of interests and values. Deliberation does not necessarily entail a coincidence of interests or priorities, but it can highlight a disproportion of advantages according to some shared values. This statement requires surmounting divisions of class, gender, rank, location, religion, community, and other established barriers with which injustices are often linked.

From this, along with "an objective analysis of the contrast between what is happening and what could have happened" (Sen 2009, p. 389), "responsibility" can emerge. Undeniably, when disadvantage is clearly exposed within an open and public framework of thought, it is then very hard to pretend to be unaware of it. In the context of deliberation, a sentiment of responsibility, or at least the conditions for its emergence, is thus enforced. Indeed, the outcome of the collective deliberation is the part-responsibility of each individual rather than of an anonymous collective body. In other words, the sentiment of responsibility for the consequences of one's claim frames the expression of individual judgments. The latter, once embedded in deliberation, are thus together more likely to generate a good outcome.

34 Sen (2009) devotes chapter 9 to a discussion of this issue. Among the other reasonable behaviours towards others that would be an important basis for impartial reasoning, Sen refers to "unilateral obligations because of asymmetry of power" used in contemporary human rights activism and to "the invoking of the device of the impartial spectator in enlightening people about moral concerns and obligations" (p. 207).

35 For instance, Sen reflects that "Sometimes the so-called 'individual' rankings and priorities can be seen not as those of distinct persons, but of different approaches by the same person to the decisional issues involved, all of which could command some respect and attention" (2009, p. 109). This can be seen as deliberation by the individual with himself. 
In fact Sen admits that he shares some of Jürgen Habermas's ideas regarding a procedural approach, but, given that it also imposes a lot of precise requirements for public deliberation, thinks that it does not differ from the reasoning strategy offered by Rawls - thus setting aside all the debates which have pitted these two authors against each other (Sen, 2009, p. 43). Sen thus suggests an interpretation of Rawls's idea of public reason that coincides with what Peter (2007) calls "rational proceduralism," as distinguished from "pure proceduralism." This means that a democratic decision is legitimate if its content is rationally justified, whereas in the case of pure proceduralism the only thing to count is that the decision is the result of an appropriately constrained decision-making process. Habermas is known as a defender of rational proceduralism, considering political fairness and rational justification to jointly determine democratic legitimacy: "deliberative politics acquires its legitimating force [...] because citizens expect its results to have a reasonable quality" (Habermas, 1996, p. 304). Rawls's comments regarding the link between process legitimacy and results are ambiguous, but Peter (2007) provides a rather convincing defense of the pure-proceduralism interpretation, particularly because Rawls's response to Habermas would not make sense if they shared the same rational proceduralism and because he has increasingly insisted that the process of decision-making should be in line with the group's shared values. Sen's interpretation tends to reveal his inclination towards rational proceduralism rather than pure proceduralism, which would also be coherent with his inclination for "broad consequentialism" rather than "broad deontology": collective decisions must not only emerge from deliberation, but must be supported by substantive reasons that everyone can accept.

The category of "rational proceduralism" is without doubt a better term with which to describe Sen's comparative approach to justice than his own term "broad consequentialism," given that he lays emphasis on the importance of the procedure that leads to a social decision or judgment: "An appropriate understanding of social realization [...] has to take the comprehensive form of a process-inclusive broad account" (Sen, 2009, p. 24). His theory can be summed up as follows: it is a comprehensive search for social agreements through (potentially incomplete) rankings of alternatives, which can be realized based on individual values and public reasoning. The importance of public debate is related to Sen's faith in people's capacity to reason about and to scrutinize their own decisions, as well as those of others. And, as discussion, context, and the people involved evolve over time, Sen opts for the social choice approach rather than that of the social contract. 


\section{Conclusion}

If Sen's and Rawls's approaches to justice are evaluated according to a common interpretation according to which a theory of justice must include precise aggregative and redistributive principles, we are led ineluctably to conclude that Sen's approach is incomplete. But reasoning this way amounts to positioning his later work within the contractualist approach or a comprehensive perspective of the just, which is clearly not the perspective that Sen adopts. Rather, Sen's aim is to induce a profound shift in the manner of reflection adopted by the established traditions. His contribution to theories of justice is generally perceived as exclusively centered on individual advantage, with a preference for focusing on individual capabilities rather than utility or primary goods. However, I have shown that he ends up going much further, and The Idea of Justice clarifies his ambitions, as well as the scope of his reflections on objectivity, which previously he himself had not fully grasped.

This conclusion is perhaps not so surprising once we recall, with Majumbar, how Sen had concluded Collective Choice and Social Welfare:

He had the feeling that the pure systems of collective choice analysis that then existed did not seem to him to be the most useful systems to study and that he had been concerned with the study of "impurities" of one kind or another, for example, partial interpersonal comparability, partial cardinality of the utility measure, restricted domains of choice, intransitive social indifference, incomplete social preference and so on. [...] He found these impurities more relevant for both "institutions" and "framework of thought". It is not that once a strong resolve is made in the mind the rest is routine. [The] Human mind is not made that way. (Majumbar 1998, p. 2860, my emphasis)

Sen has indeed been faithful to his original methodological perspective: seeking out the impurities that both economic and philosophical theorization abhors. His treatment of justice could not be resolved simply by posing one question - "what is just?" - and pure concepts of justice were necessarily to be seen as redundant and useless. Concerning procedure, then, we see two major disagreements with Rawls. First, Sen rejects the idea of the veil of ignorance which aims to allow individual judgments regardless of individual position. Second, Sen is skeptical about the assumption that, if the original position were conceivable, this hypothetical situation of primordial equality would induce a unanimous choice of a unique set of two principles of justice.

Rawls, too, has evolved, and as Peter (2007, p. 132) points out, the core concept in his latest work is not so much that of justice, but of legitimacy. This means that the question is no longer "What is the good and how it should be distributed?" but "How should democratic 
decisions be made?" In a way, this moves us more onto Sen's territory - and indeed, Sen's background in social choice theory has played a critical part in his idea of justice, alongside the new issue of deliberation. Sen champions an ethics of democracy that goes far beyond the mere possibility of voting, and yet is consistent with his first attempts to include justice criteria in Arrow's axiomatization. Individual preferences still play a role - unsurprisingly, given Sen's attachment to democracy - but the only preferences to count are those which consider the other and which are built with the other, through deliberation. He rejects the "disengaged tolerance" that has dominated normative economics in the twentieth century and has permitted theorists to avoid reasoning and discussing conflictive positions. He would rather refer to John Stuart Mill's idea of "a government by discussion," according to which the success of a democracy depends on the extent to which people's voices can be heard. In this manner, his aim is to link the concept of legitimacy to that of justice.

Finally, according to Sen, the social contract tradition has such serious limitations in providing an underpinning for a theory of justice that it ultimately serves as a barrier to practical reasoning on matters of justice. In contrast, his social choice approach is intentionally incomplete, in that it forbids any doctrinal closure. And for good reason: it is influenced by a political philosophy of deliberation, a moral philosophy based on needs and an empirical approach to engaging with social and economic facts. In other words, Sen denies the possibility that any social or political issue could be totally and definitively understood, and he rejects the idea that there could be a policy that could fully master the future. $\mathrm{He}$ believes that we have to acknowledge our human aptitudes for reasoning, argument, sympathy, and cooperation in order to strengthen the general pursuit of justice. His inclination for a kind of rational proceduralism can, however, be seen as a weakness, given his deliberately vague conception of deliberation. In contrast, Rawls's idea of public reason can be interpreted as a kind of pure proceduralism, because he has really thought about the appropriate constraints on the deliberative process. Thus, although deliberation appears as a major factor within his democratic approach to justice, Sen has not gone very far with respect to cashing out what such deliberation really involves.

\section{References}

Arrow, K.J. (1951), Social Choice and Individual Values, Cowles Foundation For Research, Yale University.

Arrow, K.J. (1973), “Some Ordinalist-Utilitarian Notes on Rawls' Theory of Justice,” Journal of Philosophy, 70 (9), pp. 245-263. 
Baujard, A., Gilardone, M. \& Salles, M. (2013), “A Conversation with Amartya Sen,” Social Choice and Welfare, forthcoming, video excerpts online: http://www.unicaen.fr/recherche/mrsh/forge/4611

Gilardone, M., Baujard, A. (2012), “A Possible Social Choice: Democracy and Positional Judgments", Working paper 2012, Université de Caen CREM CNRS; Previous version presented at the 11th Meeting of Society for Social Choice and Welfare, New Delhi, India, August 17-20.

Gilardone, M. (2010), “Amartya K. Sen: The Idea of Justice. The Belknap Press of Harvard University Press, Cambridge, Massachusetts, 2009, 468 pp," Social Choice and Welfare, 35 (4), pp. 709-720.

Habermas, J. (1996), Between Facts and Norms, trans. W. Rehg. Cambridge, MA, MIT Press. Harsanyi, J.C. (1953), "Cardinal Utility in Welfare Economics and the Theory of RiskTaking," Journal of Political Economy, 61 (5), pp. 434-435.

Harsanyi, J.C. (1955), "Cardinal Welfare, Individualistic Ethics, and Interpersonal Comparisons of Utility," Journal of Political Economy, 63 (4), pp. 309-321.

Harsanyi, J.C. (1975), "Non Linear Social Welfare Functions: Do Welfare Economists Have a Special Exemption from Bayesian Rationality?," Theory and Decision, 6 (1/4), pp. 311-332.

Harsanyi, J.C. (1977), "Non-linear Social Welfare Functions: A Rejoinder to Professor Sen," in: Butts, R.E. \& Hintikka, J. (eds.), Foundational Problems in the Special Sciences, Dordrecht, D. Reidel, pp. 293-296.

Majumbar, T. (1998), “Amartya Sen in Search of Inpure Welfare Economics - Finding New Space," Economic and Political Weekly, Vol. 33, No. 45 (Nov. 7-13, 1998), pp. 2860-2862.

Mill, J.S. (1859), On Liberty, Boston: Ticknor and Fields, $2^{\text {nd }}$ ed., 1863.

Nagel, T. (1980), “The Limits of Objectivity," in: S. McMurrin, (ed.), Tanner Lectures on Human Values, Vol. I, S. Salt Lake City, University of Utah Press et Cambridge, Cambridge University Press, pp. 76-139.

Nagel, T. (1986), The View from Nowhere, Oxford, Clarendon Press.

Nozick, R. (1973), “Distributive Justice,” Philosophy and Public Affairs, 3 (1), pp. 45-126.

Pellé, S. (2006), “Two Conceptions of Justice: Between Sen and Rawls," 6th International Conference on the Capability Approach, 29 August - 1 September, Groningen, Netherlands; on line: http://www.hd-ca.org/pubs/6_5_Pelle.pdf

Peter, F. (2007), "Rawls' Idea of Public Reason and Democratic Legitimacy," Politics and Ethics Review, 3 (1), pp. 129-143. 
Peter, F. (2009), "Rawlsian Justice," in: Anand P. \& al. (eds.), The Handbook of Rational and Social Choice. Oxford: Oxford University Press, pp. 433-456.

Rawls, J. (1971), A Theory of Justice, The Belknap Press of Harvard University Press.

Rawls, J. (1974), "Some Reasons for the Maximin Criterion," The American Economic Review, 64 (2), pp. 141-146.

Rawls, J. (1975), “A Kantian Concept of Equality,” Cambridge Review, February, 96 (2225), pp. 94-99.

Rawls, J. (2001), Justice as Fairness: A Restatement, Harvard University Press.

Rawls, J. (1993), Political Liberalism, New York: Colombia University Press.

Robbins, L. (1938), "Interpersonal Comparison of Utility," The Economic Journal, Vol. 48., $\mathrm{n}^{\circ}$ 192, Dec., pp. 635-641.

Robeyns (2009), “Justice as Fairness and the Capability Approach,” in: Basu K. \& Kanbur R. (eds), Arguments for a Better World. Essays in Honor of Amartya Sen, Oxford University Press, pp. 397-413.

Robeyns, I. \& Brighthouse, H. (2010), "Introduction: Social Primary Goods and Capabilities as Metrics of Justice," in: Brighouse \& Robeyns (eds), Measuring Justice, Cambridge University Press, pp. 1-13.

Runciman, W. G. and Sen, A. K. (1965), “Games, Justice and the General Will,” Mind, New Series, 74 (296), pp. 554-562.

Sen, A.K. (1967), "The Nature and Class of Prescriptive Judgements," The Philosophical Quarterly, 17 (66), pp. 46-62.

Sen, A.K. (1970a), Collective Choice and Social Welfare, Advanced text books in economics, North Holland, reedit. 1979.

Sen, A.K. (1970b), "Interpersonal Comparisons and Partial Comparability," Econometrica, 38(3), pp. 393-409.

Sen, A.K. (1973), On Economic Inequality, Oxford, Clarendon Press.

Sen, A.K. (1974), "Rawls versus Bentham: An Axiomatic Examination of the Pure Distribution Problem," Theory and Decision, 4 (3/4), pp. 301-309.

Sen, A.K. (1976), "Welfare Inequalities and Rawlsian Axiomatics," Theory and decision, 7 (4), pp. 243-262.

Sen, A.K. (1977), “On Weights and Measures: Informational Constraints in Social Welfare Analysis," Econometrica, 45 (7), pp. 1539-1572.

Sen, A.K. (1979a), "Utilitarianism and Welfarism," Journal of Philosophy, 76 (9), pp. 463 489. 
Sen, A.K. (1979b), "Personal Utilities and Public Judgements: Or What's Wrong with Welfare Economics?” The Economic Journal, 89 (355), pp. 537-558.

Sen, A.K. (1980), "Equality of What?" in: McMurrin Sterling, (ed.), (1980), The Tanner Lectures on Human Values, Vol. 1, S. Salt Lake City, University of Utah Press et Cambridge, Cambridge University Press, pp. 197-220.

Sen, A.K. (1982a), "Rights and Agency," Philosophy and Public Affairs, 11 (1), pp. 3-39.

Sen, A.K. (1982b), Choice, Welfare and Measurement, Oxford, Basil Blackwell, and Cambridge Mass., MIT Press.

Sen, A.K. (1983), "Evaluator Relativity and Consequential Evaluation," Philosophy and Public Affairs, 12 (2), pp. 113-132.

Sen, A.K. (1993), "Positional Objectivity,” Philosophy and Public Affairs, 22 (2), pp. 83-135. Sen, A.K. (1999), “Autobiography,” The Nobel Prizes 1998, Tore Frängsmyr, Nobel Foundation, Stockholm; on line: http://www.nobel.se/economics/laureates/1998/senautobio.html

Sen, A.K. (2002), Rationality and Liberty, The Belknalp Press of Harvard University Press.

Sen, A. K. (2005), "Human Rights and Capabilities," Journal of Human Development, 6 (2), pp. 151-166.

Sen, A.K. (2009), The Idea of Justice, The Belknap Press of Harvard University Press, Cambridge Massachusetts.

Williams, B. (1973), Problems of the Self, Cambridge, Cambridge University Press. 